\title{
Inhibition of glutamate release by BIA 2-093 and BIA 2-024, two novel derivatives of carbamazepine, due to blockade of sodium but not calcium channels
}

\author{
António F. Ambrósio ${ }^{\mathrm{a}}$, Ana P. Silva ${ }^{\mathrm{a}}$, João O. Malva ${ }^{\mathrm{a}, \mathrm{b}}$, Patricio Soares-da-Silva ${ }^{\mathrm{c}}$, \\ Arsélio P. Carvalho ${ }^{\mathrm{a}}$, Caetana M. Carvalho ${ }^{\mathrm{a}, *}$ \\ a Department of Cell Biology, Center for Neuroscience of Coimbra, University of Coimbra, 3004-517 Coimbra, Portugal \\ ${ }^{\mathrm{b}}$ Laboratory of Biochemistry, University of Coimbra, Faculty of Medicine, 3004-517 Coimbra, Portugal \\ ${ }^{\mathrm{c}}$ Department of Research \& Development, Bial, 4785 S. Mamede do Coronado, Portugal
}

Received 25 July 2000; accepted 3 December 2000

\begin{abstract}
We investigated the mechanism(s) of action of two new putative antiepileptic drugs (AEDs), (S)-(-)-10-acetoxy-10,11-dihydro-5Hdibenz $[b, f]$ azepine-5-carboxamide (BIA 2-093) and 10,11-dihydro-10-hydroxyimino-5 $H$-dibenz[ $b, f]$ azepine-5-carboxamide (BIA 2-024), by comparing their effects on the release of endogenous glutamate in hippocampal synaptosomes, with those of carbamazepine (CBZ) and oxcarbazepine (OXC). The AEDs inhibited the release of glutamate evoked by 4-aminopyridine (4-AP) or veratridine in a concentration-

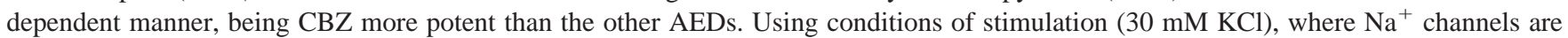
inactivated, the AEDs did not inhibit either the $\mathrm{Ca}^{2+}$-dependent or -independent release of glutamate. The results indicate that BIA 2-093 and BIA 2-024 have sodium channel-blocking properties, but CBZ and OXC are more potent than the new AEDs. Moreover, the present data also indicate that $\mathrm{Ca}^{2+}$ channels coupled to the exocytotic release of glutamate and the activity of the glutamate transporter were not affected by the AEDs. (C) 2001 Elsevier Science Inc. All rights reserved.
\end{abstract}

Keywords: Antiepileptic drugs; Carbamazepine; Oxcarbazepine; Sodium channels; Calcium channels; Glutamate release

\section{Introduction}

During the last decade several new AEDs have been developed to treat epilepsy, such as OXC, which is an analogue of CBZ, and is generally accepted as a better tolerated drug [1]. (S)-(-)-10-acetoxy-10,11-dihydro-5 $\mathrm{H}$ dibenz $[b, f]$ azepine-5-carboxamide (BIA 2-093) [2] and 10,11-dihydro-10-hydroxyimino- $5 H$-dibenz $[b, f]$ azepine5-carboxamide (BIA 2-024) [3] are new putative AEDs, chemically related to CBZ and OXC, but specifically designed to prevent the production of toxic metabolites.

\footnotetext{
* Corresponding author. Tel.: +351-239-833.369; fax: +351-239822.776 .

E-mail address: cmcarv@cnc.cj.uc.pt (C.M. Carvalho).

Abbreviations: AED, antiepileptic drug; CBZ, carbamazepine; OXC, oxcarbazepine; and 4-AP, 4-aminopyridine.
}

The mechanisms underlying the effects of the AEDs are still a matter of debate. It has been shown that CBZ and OXC inhibit voltage-sensitive sodium [4,5] and calcium currents [6,7], and that BIA 2-093 has sodium channel-blocking properties [2]. We recently found that CBZ inhibits L-type $\mathrm{Ca}^{2+}$ channels in hippocampal neurons [8].

Focal application of glutamate to the surface of the cerebral cortex evokes local epileptiform activity. Thus, inhibition of glutamate release may contribute to the efficacy of anticonvulsants against epileptic seizures. In the present work, we investigated the effects of the anticonvulsants on the release of endogenous glutamate from hippocampal nerve terminals, particularly their possible interaction with the $\mathrm{Na}^{+}$and $\mathrm{Ca}^{2+}$ channels present in nerve terminals, namely P/Q-type channels, which have a predominant role on the exocytotic release of glutamate [9]. 


\section{Materials and methods}

\subsection{Preparation of synaptosomes}

A partially purified synaptosomal fraction $\left(\mathrm{P}_{2}\right)$ was isolated from the hippocampi of male Wistar rats (2 months of age) as described previously [9].

\subsection{Endogenous glutamate release experiments}

The release of endogenous glutamate was followed by using a continuous fluorimetric assay, as previously described [10]. The synaptosomes $(1 \mathrm{mg})$ were incubated for $30 \mathrm{~min}$ at $37^{\circ} \mathrm{C}$ in the following medium (in $\mathrm{mM}$ ): 132 $\mathrm{NaCl}, 1 \mathrm{KCl}, 1 \mathrm{MgCl}_{2}, 1.2 \mathrm{H}_{3} \mathrm{PO}_{4}, 0.1 \mathrm{CaCl}_{2}, 10$ glucose, 10 HEPES-Na, at $\mathrm{pH} 7.4$, with $0.1 \%$ fatty acid-free bovine serum albumin (BSA), centrifuged, and then resuspended in $1 \mathrm{ml}$ of the same medium with $1 \mathrm{mM}$ NADP, $50 \mathrm{U}$ of purified L-glutamic acid dehydrogenase type II (EC 1.4.1.3; Sigma), $1 \mathrm{mM} \mathrm{CaCl}$ or with $200 \mathrm{nM}$ free $\mathrm{Ca}^{2+}$ (without BSA).

Fluorescence was measured by using a luminescence spectrometer (Perkin Elmer model LS-5B) at excitation and emission wavelengths of $340 \mathrm{~nm}$ and $460 \mathrm{~nm}$, respectively, with excitation and emission slits of $5 \mathrm{~nm}$ and $10 \mathrm{~nm}$, respectively. The data were collected at $0.5 \mathrm{~s}$ intervals and the quantitation of glutamate release was performed at the end of each experiment by adding $2.5 \mathrm{nmol}$ of L-glutamate.

\subsection{Chemicals and data analysis}

Carbamazepine, oxcarbazepine, BIA 2-093 and BIA 2-024 were obtained from BIAL, S. Mamede do Coronado, Portugal. Veratridine, 4-AP, tetrodotoxin, NADP and Lglutamic acid dehydrogenase type II (EC 1.4.1.3) were purchased from Sigma Chemical Co. All other reagents were from Sigma or from Merck-Schuchardt, Germany. CBZ, OXC, BIA 2-093, BIA 2-024 and veratridine stock solutions were prepared in DMSO.

The data are expressed as means \pm SEM. Statistical significance was determined by using an analysis of variance (ANOVA), followed by Dunnett's post-test. The dose-inhibition curves for the effects of CBZ, OXC, BIA 2-093 and BIA 2-024 represent the best fit according to nonlinear regression analysis (one site competition), assuming bottom and top values of $0 \%$ and $100 \%$, respectively.

\section{Results and discussion}

Stimulation of hippocampal synaptosomes with $100 \mu \mathrm{M}$ 4 -AP evoked the release of $4.6 \pm 0.1 \mathrm{nmol}$ glutamate $/ \mathrm{mg}$ protein $/ 5 \mathrm{~min}$, and the AEDs inhibited the release of glutamate, as illustrated in Fig. 1, in a concentration-dependent manner (Fig. 2). Carbamazepine was more potent than
A

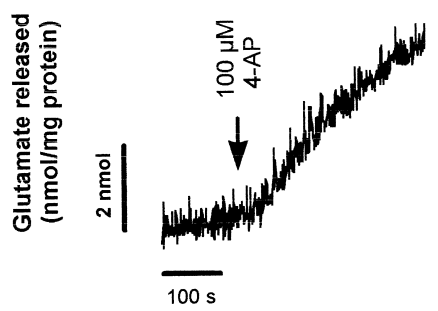

B + CBZ

Fig. 1. Illustrative recordings of endogenous glutamate release stimulated by $100 \mu \mathrm{M} 4-\mathrm{AP}$ in hippocampal synaptosomes $\left(1 \mathrm{mM} \mathrm{Ca}^{2+}\right.$ present in the external medium). Synaptosomes were stimulated for 5 min with 4-AP, and the AEDs were present since the beginning of the experiment. (A) Control (B) Effect of $300 \mu \mathrm{M} \mathrm{CBZ}$.

OXC, BIA 2-093 or BIA 2-024. The $\mathrm{IC}_{50}$ values for CBZ, OXC, BIA 2-093 or BIA 2-024 were 99.3 $\pm 1.08 \mu \mathrm{M}$, $156.8 \pm 1.23 \mu \mathrm{M}, 233.0 \pm 1.14 \mu \mathrm{M}$ or $188.0 \pm 1.13 \mu \mathrm{M}$, respectively.

Veratridine $(5 \mu \mathrm{M})$ evoked the release of $6.6 \pm 0.2$ nmol glutamate/mg protein/5 min. Again, the AEDs inhibited the release of glutamate in a concentration-dependent manner (Fig. 3), and CBZ was again more potent than OXC, BIA 2-093 or BIA 2-024. The $\mathrm{IC}_{50}$ values for CBZ, OXC, BIA 2-093 or BIA 2-024 were $123.9 \pm 1.07$ $\mu \mathrm{M}, 156.9 \pm 1.15 \mu \mathrm{M}, 232.3 \pm 1.07 \mu \mathrm{M}$ or $190.8 \pm$ $1.11 \mu \mathrm{M}$, respectively.

When synaptosomes were stimulated with $30 \mathrm{mM} \mathrm{KCl}$ the release of glutamate was $6.8 \pm 0.5 \mathrm{nmol}$ glutamate $/ \mathrm{mg}$ protein $/ 5 \mathrm{~min}$. The $\mathrm{Ca}^{2+}$-independent glutamate release was $36.7 \pm 2.9 \%$ of total release (data not shown). Moreover, 1 $\mu \mathrm{M}$ tetrodotoxin did not inhibit the release of glutamate evoked by $30 \mathrm{mM} \mathrm{KCl}$ (data not shown), indicating that voltage-sensitive sodium channels are inactivated. The AEDs $(300 \mu \mathrm{M})$ did not inhibit the $\mathrm{KCl}$-evoked (exocytotic plus non-exocytotic) glutamate release (data not shown). Also, the AEDs did not inhibit the non-exocytotic $\mathrm{KCl}-$ evoked glutamate release $\left(200 \mathrm{nM}\right.$ external $\mathrm{Ca}^{2+}$, data not shown).

In the present study, we investigated the effects of BIA 2-093, BIA 2-024, CBZ and OXC on the exocytotic and/or carrier-mediated release of endogenous glutamate in hippocampal nerve terminals. As shown previously, $\mathrm{P} / \mathrm{Q}$-type $\mathrm{Ca}^{2+}$ channels have a predominant role on the exocytotic release of endogenous glutamate [9]. Because CBZ [6,8] and OXC [7] inhibit calcium channels, we investigated whether the AEDs could inhibit P/Q-type calcium channels present in nerve terminals. The inhibitory effect caused by the AEDs on the release of glutamate evoked by 4-AP or veratridine could be due either to the inhibition of sodium channels, to the inhibition of calcium channels coupled to the exocytotic release of glutamate, or in part due to the inhibition of the glutamate transporter. However, the AEDs did not inhibit the release of glutamate when sodium channels are inactivated 
A
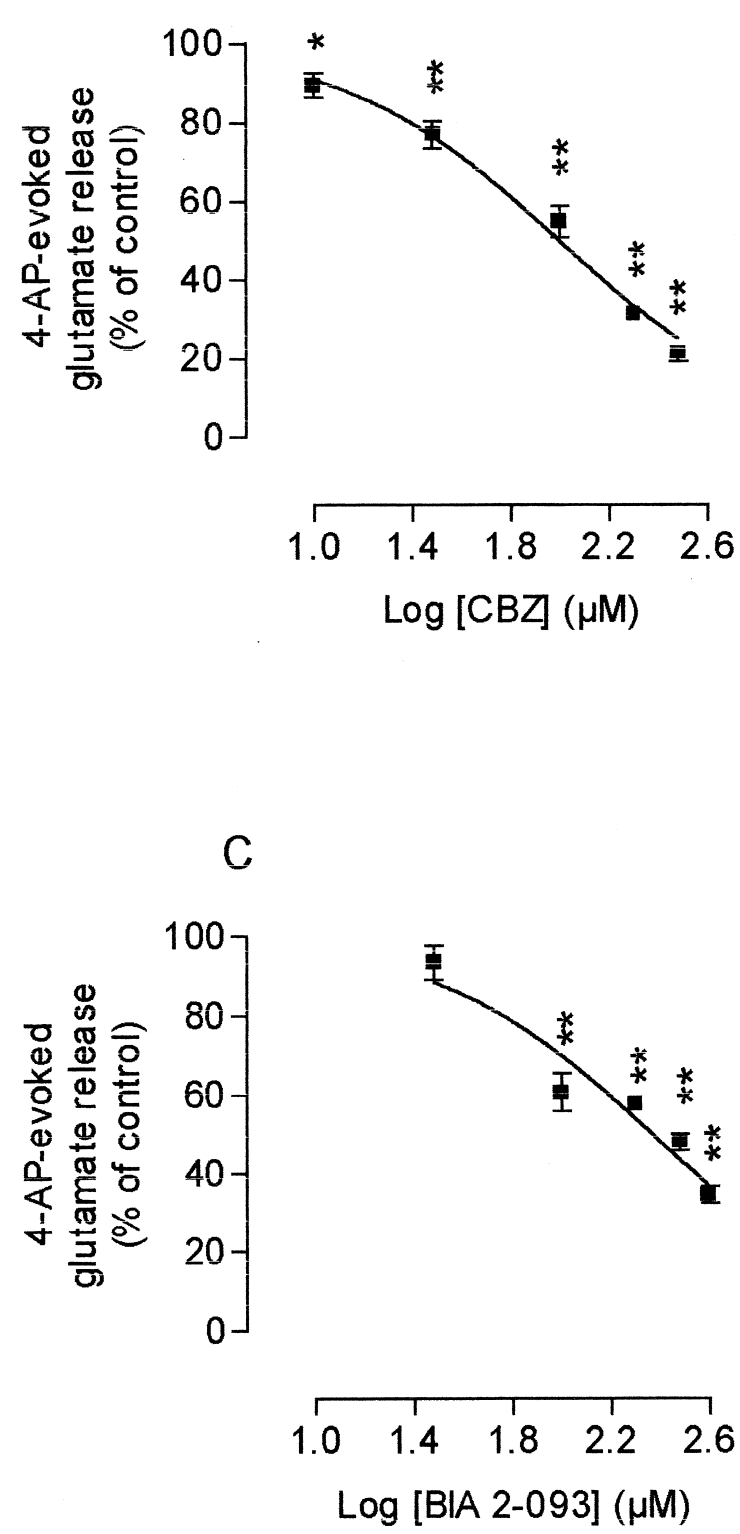

B

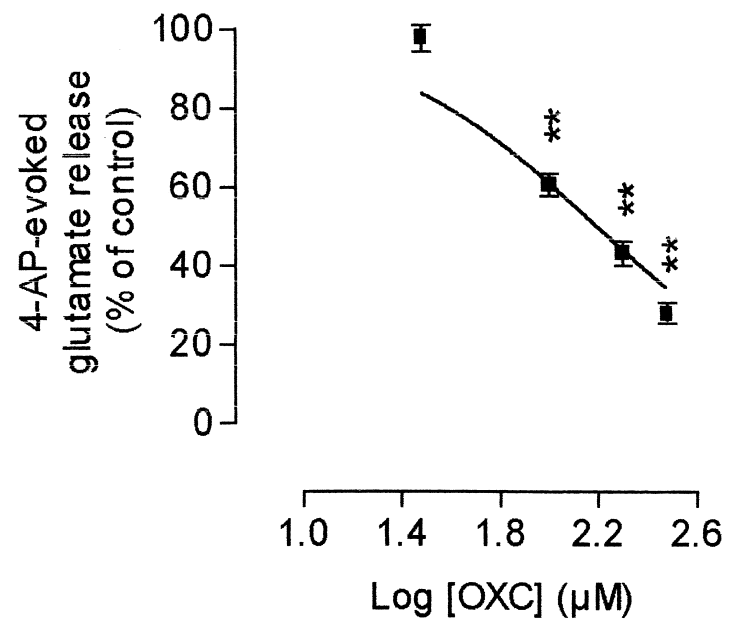

$\mathrm{D}$

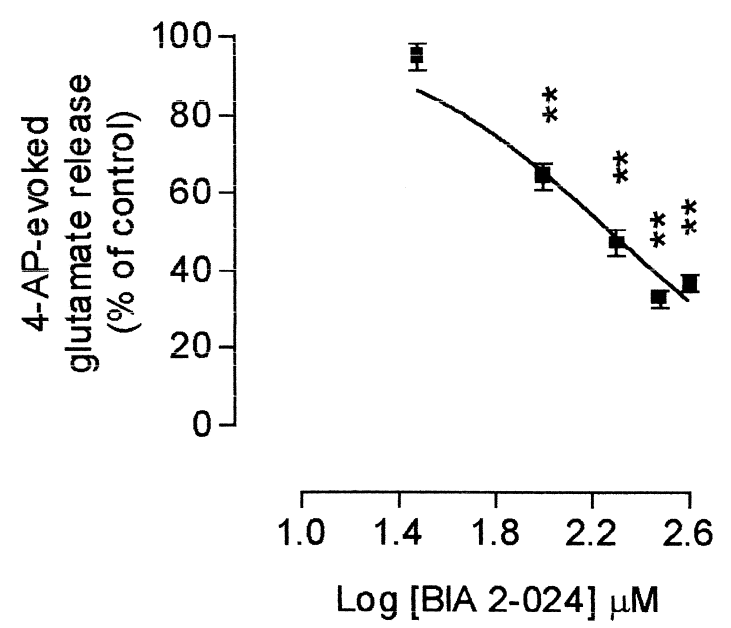

Fig. 2. Dose-inhibition curves for the effect of CBZ, OXC, BIA 2-093 or BIA 2-024 on the release of endogenous glutamate evoked by $100 \mu \mathrm{M} 4-\mathrm{AP}$ (1 $\mathrm{mM} \mathrm{Ca}{ }^{2+}$ present in the external medium). The results represent the mean \pm s.e.m. of three to eight independent experiments, in different synaptosomal preparations, and are presented as percentage of control. ${ }^{*} P<0.05$; $* * P<0.01$-Dunnett's post-test; Statistical significance when compared to control (4-AP stimulation).

(stimulation with $30 \mathrm{mM} \mathrm{KCl}$ ), indicating that the inhibition caused by the AEDs on the 4-AP- or veratridineevoked glutamate release was due to the inhibition of sodium channels and not to the inhibition of calcium channels or the glutamate transporter.

It was previously shown that CBZ and OXC inhibit the release of glutamate elicited by veratrine or veratridine $[11,12]$, however it is uncertain whether these effects are relevant in vivo at anticonvulsant doses. It was also reported that CBZ inhibits glutamate release by preferentially blocking sodium channels [13]. In the present work, the release of glutamate stimulated by 4 -AP or veratridine was significantly inhibited by $\mathrm{CBZ}$ at concentrations similar to those found in plasma levels (17-51 $\mu \mathrm{M})$ [14]. Since OXC, BIA 2-093 and BIA 2-024 significantly inhibited the release of glutamate at higher concentrations, it is not clear whether these effects are relevant in vivo.

In conclusion, our results show that BIA 2-093 and BIA 2-024 have antagonistic properties on sodium channels, however with lower potency when compared to CBZ or OXC. The AEDs tested neither affected the calcium channels, which are coupled to the exocytotic release of glutamate, nor the glutamate transporter. 

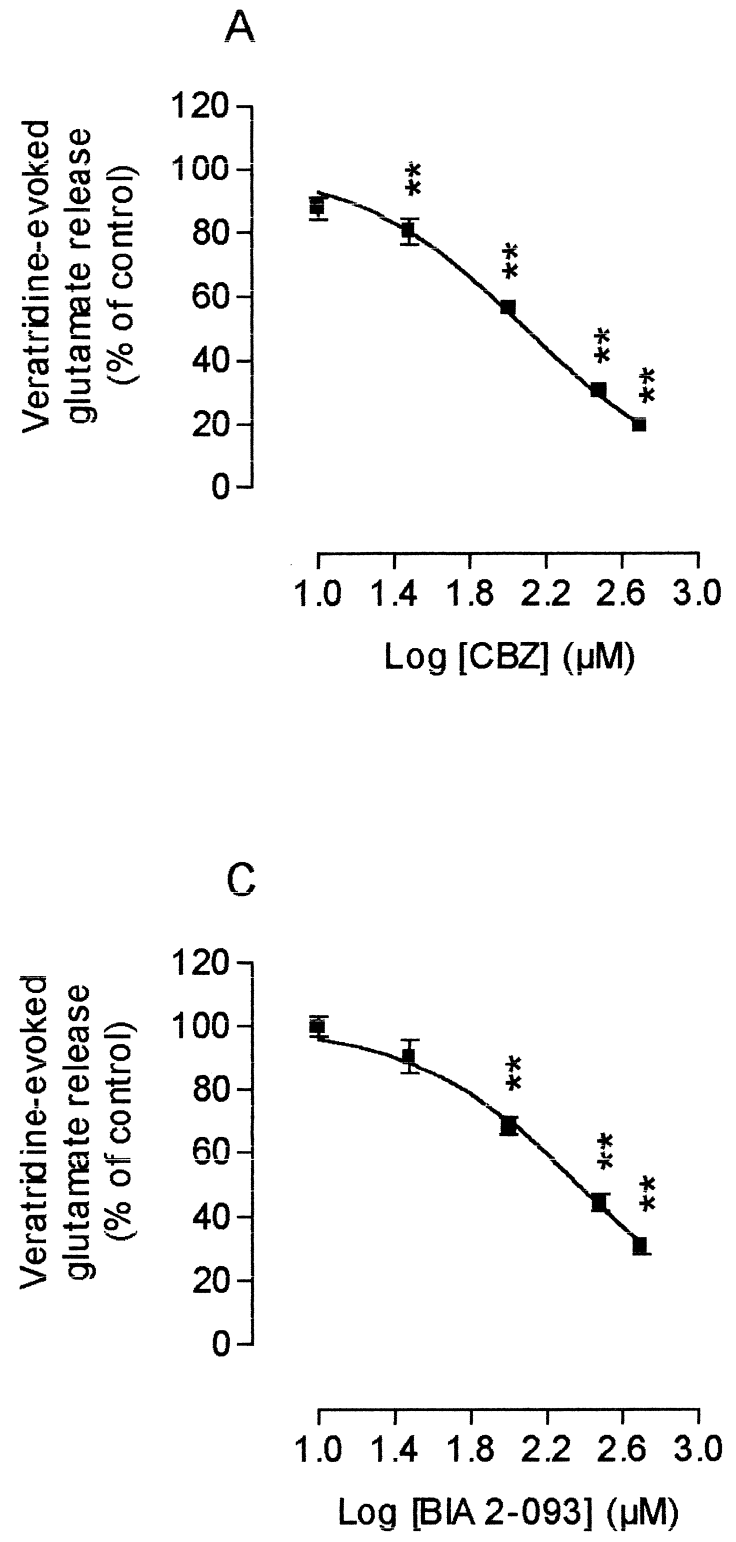

B

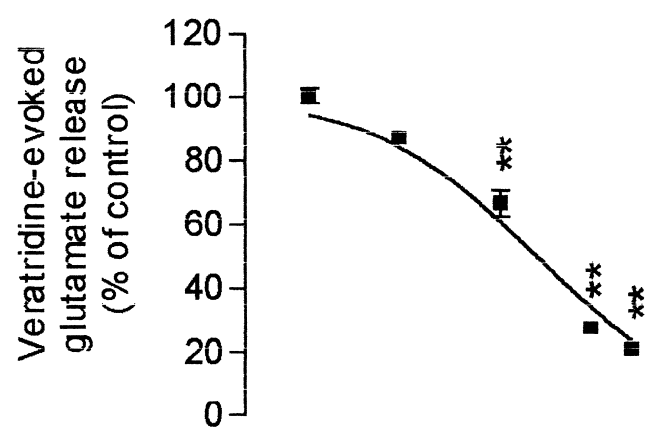

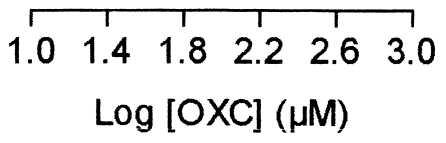

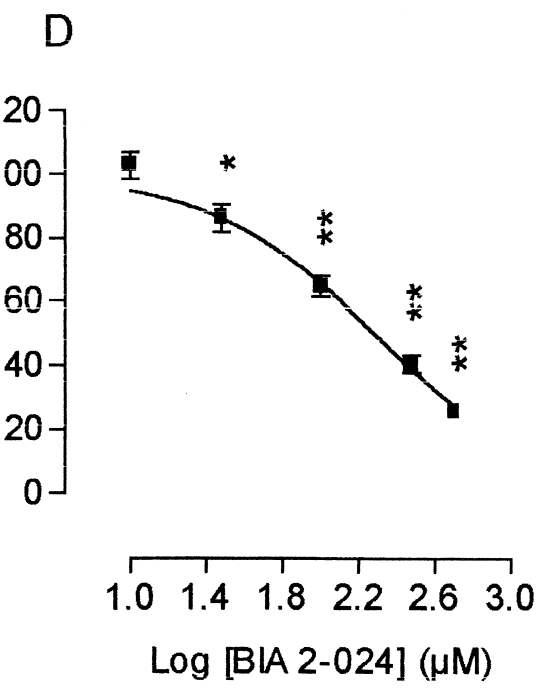

Fig. 3. Dose-inhibition curves for the effect of CBZ, OXC, BIA 2-093, or BIA 2-024 on the release of endogenous glutamate evoked by $5 \mu$ M veratridine $\left(1 \mathrm{mM} \mathrm{Ca}^{2+}\right.$ present in the external medium). The results represent the mean \pm s.e.m. of three to five independent experiments, in different synaptosomal preparations, and are presented as percentage of control. $* P<0.05$; $* * P 0.01$-Dunnett's post-test; Statistical significance when compared to control (veratridine stimulation).

\section{Acknowledgments}

This work was supported by Fundação para a Ciência e a Tecnologia, Programa PRAXIS XXI, Portugal (grant PRAXIS XXI 5604/95) and by BIAL, Portugal.

\section{References}

[1] Grant SM, Faulds D. Oxcarbazepine. A review of its pharmacology and therapeutic potential in epilepsy, trigeminal neuralgia and affective disorders. Drugs 1992;43:873-88.

[2] Benes J, Parada A, Figueiredo AA, Alves PC, Freitas AP, Learmonth DA, Cunha RA, Garrett J, Soares-da-Silva P. Anticonvulsant and sodium channel-blocking properties of novel 10,11-dihydro-5 $\mathrm{H}$ dibenz $[b, f]$ azepine-5-carboxamide derivatives. J Med Chem 1999; 42:2582-7.

[3] Benes J, Soares-da-Silva P, Learmonth DA. Derivatives of 10,11dihydro-10-oxo-5H-dibenz $[b$ f $]$ azepine-5-carboxamide. United States Patent. Patent Number 5,866,566, 1999.

[4] Kuo CC, Chen RS, Lu L, Chen RC. Carbamazepine inhibition of neuronal $\mathrm{Na}^{+}$currents-quantitative distinction from phenytoin and possible therapeutic implications. Mol Pharmacol 1997;51:1077-83.

[5] Löscher W. New visions in the pharmacology of anticonvulsion. Eur J Pharmacol 1998;342:1-13.

[6] Schumacher TB, Beck H, Steinhäuser C, Schramm J, Elger CE. Effects of phenytoin, carbamazepine, and gabapentin on calcium channels in hippocampal granule cells from patients with temporal lobe epilepsy. Epilepsia 1998;39:355-63. 
[7] Stefani A, Pisani A, de Murtas M, Mercuri NB, Marciani MG, Calabresi P. Action of GP 47779, the active metabolite of oxcarbazepine, on the corticostriatal system. II. Modulation of high-voltageactivated calcium currents. Epilepsia 1995;336:997-1002.

[8] Ambrósio AF, Silva AP, Malva JO, Soares-da-Silva P, Carvalho AP, Carvalho CM. Carbamazepine inhibits L-type $\mathrm{Ca}^{2+}$ channels in cultured hippocampal neurons stimulated with glutamate receptor agonists. Neuropharmacology 1999;38:1349-59.

[9] Ambrósio AF, Malva JO, Carvalho AP, Carvalho CM. Inhibition of $\mathrm{N}-, \mathrm{P} / \mathrm{Q}-$ and other types of $\mathrm{Ca}^{2+}$ channels in rat hippocampal nerve terminals by the adenosine $\mathrm{A}_{1}$ receptor. Eur J Pharmacol 1997;340: $301-10$.

[10] Nicholls DG, Sihra TS, Sanchez-Prieto J. Calcium-dependent and -independent release of glutamate from synaptosomes monitored by continuous fluorometry. J Neurochem 1987;49:50-7.
[11] Waldmeier PC, Baumann PA, Wicki P, Feldtrauer JJ, Stierlin C, Schmutz M. Similar potency of carbamazepine, oxcarbazepine, and lamotrigine in inhibiting the release of glutamate and other neurotransmitters. Neurology 1995;45:1907-13.

[12] Waldmeier PC, Martin P, Stocklin K, Portet C, Schmutz M. Effect of carbamazepine, oxcarbazepine and lamotrigine on the increase in extracellular glutamate elicited by veratridine in rat cortex and striatum. N-S Arch Pharmacol 1996;354:164-72.

[13] Lingamaneni R, Hemming HC. Effects of anticonvulsants on veratridine- and $\mathrm{KCl}$-evoked glutamate release from rat cortical synaptosomes. Neurosci Lett 1999;276:127-30.

[14] Rogawski MA, Porter RJ. Antiepileptic drugs: pharmacological mechanisms and clinical efficacy with consideration of promising developmental stage compounds. Pharmacol Rev 1990;42:22386. 